\title{
A Conceptual Urban Quality Space-Place Framework: Linking Geo-Information and Quality of Life
}

\author{
Pablo F. Cabrera-Barona ${ }^{1,2, *}$ and Helena Merschdorf ${ }^{3}$ \\ 1 Center for Government and Public Administration, Instituto de Altos Estudios Nacionales-IAEN, \\ Quito 170135, Ecuador \\ 2 School of Public Health, Universidad San Francisco de Quito-USFQ, Quito 170157, Ecuador \\ 3 Department of Geoinformatics-Z_GIS, University of Salzburg, Salzburg 5020, Austria; \\ helenamerschdorf@gmail.com or helena.merschdorf@stud.sbg.ac.at \\ * Correspondence: pablo.cabrera@iaen.edu.ec or pablo.cb@live.com; Tel.: +593-960-192-652
}

Received: 6 August 2018; Accepted: 17 August 2018; Published: 23 August 2018

\begin{abstract}
Space and place are key concepts for understanding the functionality of social and environmental interactions. Cities are complex social-ecological systems where space-place interactions can be interpreted by means of quality of life. Firstly, we present several quality-of-life concepts that can be linked to space and place concepts. Secondly, we develop an analysis about space and place interactions, and how the social aspects, such as the sense of place, and physical aspects, such as urban spaces, are associated with quality of life and inclusive places. Thirdly, we state how the quality of life definitions of livability and life-ability are linked to the space and place concepts, and how this link can support the understanding of quality of life in cities, considering spatial thinking. Fourthly, we expand geo-information theories to a space-place approach of urban quality of life. Finally, we discuss how the developed conceptual framework can be applied to interpret the smart city. This paper contributes to the construction of new epistemologies that could support a more holistic understanding of the cities and a more social and humanistic use of geo-information and technology.
\end{abstract}

Keywords: space; place; quality of life; geoinformation

\section{Introduction}

Our vision of reality is based on a three-dimensional (3D) world. Objects and events in the world have relative positions and directions in this three-dimensional environment [1]. This is the spatial notion of the world, and this notion can be applied to the understanding of different systems, just as social-ecological systems, which can be expressed in terms of spatial heterogeneity of urban environments [2]. For instance, a spatial pattern of a city, such as land surface temperature, can be associated with population density by means of geo-information analyses of spatial information [3].

Brenner and Schmid [4] interpret the urban sphere as a "multi-scalar process of socio-spatial transformations". They argue that the concept of the urban cannot be defined as an empirical object or a bounded unit, but as a dynamic, complex process that can be framed by theoretical categories. In these terms, it is important to overcome the simplistic Euclidean notions that treat space/place as definable objects [5]. Place is a more complex concept than space-notwithstanding, referenced by space- that enables the understanding of the reality as it is, a complex dynamic process represented by the collective construction of individual actions. These actions are directly related to the sense of place; how people behave depends on how they interpret their role in the environment where they are located. Place is specific because it can be considered as a meta-concept that describes particular stories in a more general conception, the space (location) [6]. Individual human characteristics influence the 
sense of place, and these characteristics belong to diverse domains (i.e., social, psychological, spiritual, and economic well-being) that define an individual's quality of life [7]. The concept of quality of life is multidimensional, dynamic, and context-dependent, and is usually related to the terms of happiness and well-being. Additionally, there is widespread interest in understanding quality of life in the context of place and urban space [8]. The urban environment is a complex multi-scale dynamic process in which people interact through multiple spatialities. We argue that conceptual frameworks need to be developed to operationalize the analyses of quality of life connected to the notions of space and place.

In this paper, we consider quality of life in the city as an interaction of different qualities of life in a dynamic space-place complex process, defined by urban societies and their people. We also argue that the societies and their people are ultimately the convergence point where the space-place concept can be developed. A basic idea is that society is a complex evolving system that defines an evolving urban process.

\section{The Quality of Life}

Quality of life is a multi-faceted concept and an interdisciplinary field of study [8]. There are diverse approaches to explaining quality of life. Glatzer [9] states that positive and negative wellbeing, as well as future expectations, define the quality of life. Thus, hopes and fears influence people's wellbeing. Quality of life is a multiscale concept representing the conditions of individuals and society. In terms of Sen's social choice theory [10], individuals' access to services and individuals' capabilities can be combined to reach social welfare. Furthermore, quality of life encompasses subjective and objective aspects of life $[9,11]$, which influence wellbeing and happiness. Analyses of objective wellbeing are subjected to experts' identification of problems that may not be completely clear for the general public, such as long-term temperature change [9]. Wellbeing is also based on objective dimensions such as economic welfare and the socio-demographics of individuals [12,13]. Subjective wellbeing can be described as the happiness of the individual and is associated with life satisfaction [14]. This quality of life, in terms of happiness, depends on the place where individuals live-scale-dependent physical and human contexts influence quality of life [15]. In the urban context, Shafer et al. [16] define quality of life as the intersection of the dimensions of community (social), the environment and economics. They also mention that the livability is the intersection between the environment and the social dimensions. When considering the environment and the notion of place in quality of life analyses, and because most of the world's population lives in cities, Marans and Stimson [8] mention the relevance of studying quality of urban life, and they consider the usefulness of quality of life indicators that can be used to measure quality of urban life in neighborhoods and cities. In general, analyzing quality of life needs to associate diverse concepts and phenomena, such as satisfaction, livability, community and people's perceptions and feelings. In this sense, we consider that Veenhoven $[14,17]$ offers an integrated and multi-dimensional perspective of quality of life, structuring the concept of quality of life using four different categories, distinguishing between opportunities related to having a good quality of life (a good life) and the outcomes that define the good life, and distinguishing between inner and outer qualities (Table 1). In terms of opportunities, quality of life can be divided into the livability of the environment (outer quality) and the life-ability of the person (inner quality). In terms of outcomes, quality of life can be divided into the utility of life (outer quality) and the satisfaction with life (inner quality). Quality of life is understood as a concept not only exclusive to individual human life, but extended to the ecological and collective level.

Table 1. The four qualities of life.

\begin{tabular}{ccc}
\hline & Outer Quality & Inner Quality \\
\hline $\begin{array}{c}\text { Life-chances } \\
\text { Life-results }\end{array}$ & $\begin{array}{c}\text { Livability of environment } \\
\text { Utility of life }\end{array}$ & $\begin{array}{c}\text { Life-ability of the person } \\
\text { Life-satisfaction }\end{array}$ \\
\hline \multicolumn{3}{c}{ Source: Veenhoven [14,17]. }
\end{tabular}




\section{The Social Understanding of Urban Space: The Inclusive Places}

The notion of place, rather than space, frames human behavior in urban environments [1]. The evaluation of urban quality of life considers the concept of place as the geography where individuals and groups of individuals interact [8]. If a city is the arena where different domains, such as economics, physical environment, and social dynamics are expressed, the space and place can be analyzed using the lens of these different domains. Economy can create the conditions that produce space [18]. Isard [19] proposed a space-economy, linking location theory with price, production, and trade, where the labor can be situated at diverse places. However, Lefebvre [20] stated that the space produced by economic transactions and state policies caused a commodification and bureaucratization of the everyday life. He argued that society needs to reclaim spaces for the everyday life. In other words, the everyday life could be improved by the construction of places (concrete spaces) that encompass the bottom-up practices of the citizens.

Matching individuals' happiness to their physical surroundings is a means to understanding the influence of space on wellbeing [13]. The urban environment (the object and the space) is related to the quality of place and livability, through the integration of the quality of the local environment and the perceptions of urban dwellers (e.g., perceived health) [12]. From a sociological point of view, the places are seen as the sites of social relations [6] by acting as open articulations of connections [21]. In this sense, the place is constructed by interconnected people with place-specific social forms expressed in the space. People think in terms of places, and place is the underlying entity in which human interaction takes place.

To clarify the difference between space and place, as we use the terms in this paper, space refers to the dimensions of height, depth, and width within which things exist and move (i.e., the cartesian notion of coordinates), whereas place refers to the human experience and perception therein. As such, place has been termed as "the conceptual fusion of space and experience" [22], and this is the basic idea of the sense of place. Thus, as presented by Jorgensen and Stedman [23], the idea that the sense of place is the experience based on attachment (sentiments toward a place), identity (beliefs associated to a place), and dependence (behaves toward a place). That means, different people may have different perceptions of a certain space, and the same spatial location may be perceived as different places. For this reason, and specifically in the case of the city, it is important to emphasize not the infrastructure, but the way in which urban residents experience the physical spaces [24]. The sense of place is a social construction and, in this sense, is dynamic, may change over time, and can constantly be re-created by the experience of each individual. Considering the place attachment, place identity, and place dependence, Acedo, Painho, and Casteleyn [25] claimed that for each individual living in a city, there is a set of meaningful places and social networks that she/he belongs to, and that these social networks can be spatially defined. From this perspective, a city with quality-of-life can be expressed as a city with spatial relationships between social cohesion and a sense of place, which facilitates the better cooperation between citizens in order to create adequate livability. In the next sections of the paper, we will develop this idea in more detail.

The relationships between space and place are not simplistic. The sense of place is embedded in a spatially structured location, Cartesian space. However, space can also be understood as the spatial structure output of perceptions, ideologies, idiosyncrasies, interpretations, and knowledge. In other words, the way we design the physical space is related to our perceptions of the world. Thus, we can interpret the productions of spaces-and places—as social practices (e.g., festivals, local markets, exercise, etc.), giving rise to the intersection of multiple spatialities [26]. In the urban environment, places are not stable or temporally homogeneous, and blend different realities originating from complex spatialities and temporalities [27]. Cities are not homogeneous, but are historical and cultural productions [28]. In this sense, a city can be described as the time-dynamic representation of multiple places that produce and are produced by diverse spatialities (e.g., urban patterns and urban structure). For instance, urban patterns such as land use intensity and heterogeneity, through different mechanisms and effects, influence social components of the city, such as urban economics 
and urban planning, and these social components are also the drivers that shape the urban patterns of the city [29].

This conception of space-place interactions is not linear, and it can be said that places also produce new urban structures and patterns, and these patterns and dynamics may create new senses of places. This dynamic social space influences the right to the city, which can be seen as the right to a good urban life [30]. The city is interpreted as the confluence of the physical and mental space, and can be defined by the dimension of human life [20]. Thus, the sense of place in the city is constantly transformed and represents the experience of urban social life, social life that needs to have the right of the appropriation of the urban space. The key aspect of Lefebvre's right to the city [30] and production of the space is that space is not a container that needs to be filled, but is fabricated by our social relations and, at the same time, space is a designer of these relations. However, Augé [31] argued that the same space can be a place and also a 'non-place'. A non-place is a space emptied of its significance-a non-meaningful space. This socio-spatial dialect allows for the recognition of spatial (in)justice phenomena in the city. Public spaces need to be inclusive and offer a healthy environment. The access to public spaces where people can generate their own sense of community is a very important issue for social justice in the city. The basic idea of spatial justice is the fair distribution of urban resources that are socially valued, and the fair access that citizens have to these resources [32]. Harvey [18] argued that inequalities cause spatial patterns in the city that undermine places of quality-of-life. Therefore, inequality and the unjust accumulation of resources undermines universal human rights. The urban geographies of (in)equality can offer an analytical panorama to understand how to improve the quality of life in the city. Figure 1 shows the confluence of the social and physical spheres from the space-place perspectives explained in this section. Urban structure and spatial patterns of urban processes influence the sense of place. Depending on the patterns and structure, the same location can be considered a place for an individual, and a non-place for another individual. At the same time, social practices can drive and shape the urban structure and spatial patterns. Pro-social behavior and equality is associated with the fair distribution of resources in the city (e.g., healthy food markets) and to the optimal accessibility to services (e.g., health services). The social and physical spheres interact with the phenomena of quality of life and inclusive places. For instance, meaningful places and clean public areas may induce better quality of life and generate inclusive places, whilst inclusive places and a perception of good quality of life can incentivize the perceptions of social equality and influence the development of new public space. Quality of life and inclusive places guarantee the right to the city and the spatial justice.

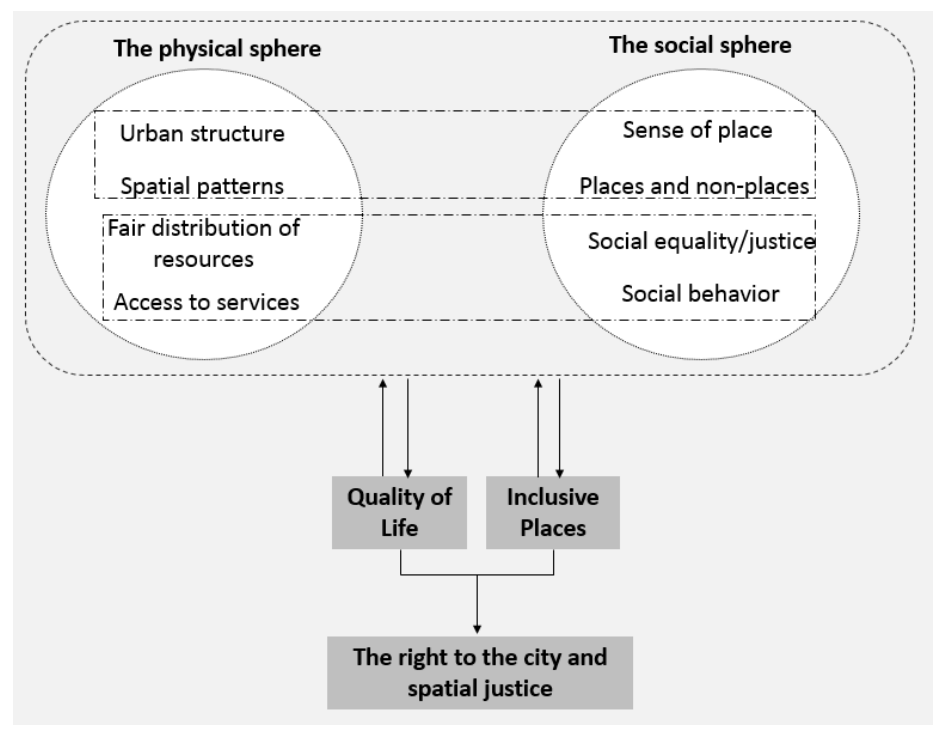

Figure 1. The physical and social spheres associated with quality of life and inclusive places guarantee the right to the city and spatial justice. 


\section{Livability, Life-Ability, and the Construction of 'Quality of Life' Places and Spaces}

Traditionally, urban planning has understood livability as the good conditions of the built environment. However, in the social-ecological view, societies are the lens to understand livability. The 'quality of society' is thought to be a central part of the livability [14]. The quality of life within a society is associated with social capital and social cohesion. Social fragmentation is seen as a phenomenon that reduces the quality of life within a society. For instance, higher first admissions for psychosis are associated with high social fragmentation [33]. Social capital is influenced by the intensity of social links constructed by trust, sharing, and reciprocity [34]. Thus, it can be said that one of the equivalents for urban livability is having cohesive communities in the city. Cohesive communities are associated with what we refer to as 'socially-vibrant' urban neighborhoods. Socially-vibrant neighborhoods are composed of cohesive groups of people that collaborate, communicate, and participate together in solutions of the community's problems. The definition of urban neighborhoods is not limited to administrative units, and neighborhood limits can be socially constructed [35]. Thus, the analysis of livability can utilize groups of individuals as the basic unit of analysis, and the spatial expression of this unit of analysis can be the urban neighborhood. Considering a systems perspective, livability could be studied by applying the social entropy theory [36]. Social entropy is minimal when the correlations of the population's variables are maximal. For instance, a low social entropy occurs when the same group of individuals have similar levels of social values and assets. Thus, a low level of entropy is necessary to maintain quality of life [37]. Moreover, urban planning should pursue a low-entropy city view, organizing spatial elements (e.g., green areas) of the city to promote social cohesion and a sense of place [38] Therefore, social cohesion can reduce the uncertainties related to entropy, because networks of attuned and conscious citizens are more able to create inclusive spaces for the livability of the city. In this context, low levels of social entropy mean a good quality of life, meaning that livability is created by communities with socio-economic equality and social cohesion. Urban planning needs to consider these conditions for livability in order to create spatial justice. For example, the revitalization of urban spaces needs to focus on social equity and justice beyond the traditional view of design and aesthetics [39].

Life-ability refers to the capability of the person, the individual characteristics to resolve problems of life [14]. Analyzing life-ability is a shift in the scale of analysis, from the social unit to the individual unit. The recognition of the life-ability of the individual is the recognition of an inner person's qualities, such as health, knowledge, and resilience $[14,17]$. A healthier and less socially vulnerable individual is more likely to create livable spaces. The life-abilities of the individual are activities to construct quality of life. This is important for the sense of place, because life-ability also requires self-actualization [14]. Self-actualization is related to the roles a person acquires during her/his life and the adaptiveness of the person to changing situations. Therefore, life-ability can also be considered as the 'inner space' of the person, the self-identification that is primordial in creating a sense of place. The individual constructs her/his place through social practices that symbolize her/his role in society. We see here that the sense of place can be considered as a link between the life-ability and livability in the urban space. Figure 2 illustrates this link in detail. Individuals with life-abilities can each have a spatial location and a sense of place associated with this location. We can aggregate individuals at a community level (group of individuals) and at the neighborhood and city level. The neighborhood/city level denotes a network of individuals' groups or the city's population. The livability for the community is based on its social cohesion that can be represented as a social network in a specific geographical space. The community may also generate a common sense of place toward this space. The urban context of a neighborhood or a whole city can be represented by the livability of its environment, and can be delineated by administrative or subjective spatial boundaries. The city and the neighborhood can have at least one meaningful place for each urban inhabitant. 


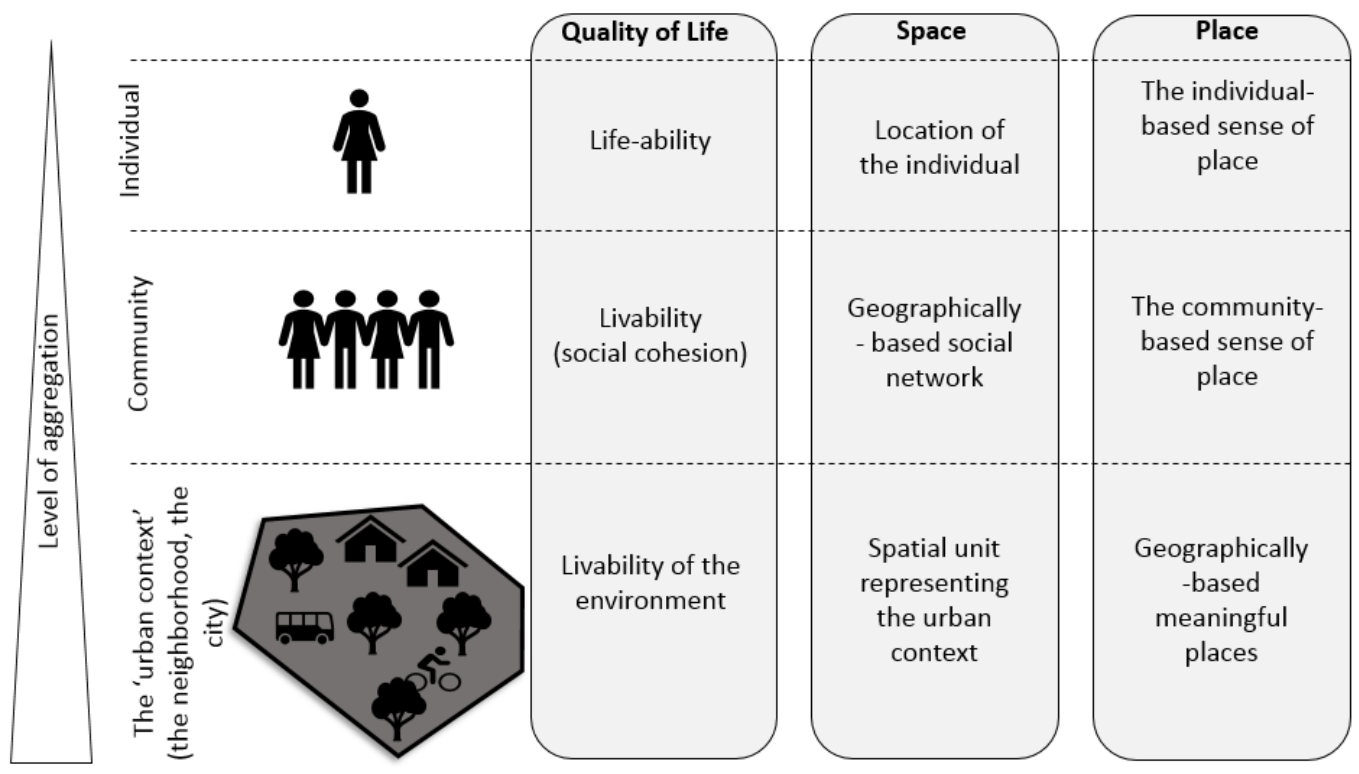

Figure 2. Relationships between quality of life, space, and place at different levels of aggregation.

\section{Expanding Geo-Information Concepts to Quality of Life: A Conceptual Urban Quality Space-Place Framework}

Geometrically, place can be defined in spatial locations, but phenomenologically, place is defined as the geographical context for the mediation of the physical environment and socio-economic processes [6]. We can consider the existence of a place as a function $z(x)$, where $z$ represents all the attributes (e.g., lifestyles) of the place located in a space, $x$ [40]. These attributes can also be located in time, which is where the concept of space-time takes relevance. The space-time concept [41] pointed out the critical importance of time when fitting individuals together in social and economic systems, considering certain levels of livability. Therefore, it can be said that the livability and the life-ability also imply that the characteristics of the environment are intrinsically connected to individuals. For instance, the life-ability of individuals can be associated with their ability to access desired services such as healthcare, or educational or green areas.

The concepts of geo-atoms, geo-objects, and geo-dipoles, proposed by Goodchild et al. [42], have been used to represent the complexity of geo-information, and to construct a general theory of geographic representation. A geo-atom is defined as the 'atomic form' of geographic information through the following tuple:

$$
<x, Z, z(x)>
$$

where $x$ defines a location in space-time (four dimensions), $Z$ represents an identified property, and $z(x)$ defines the particular value of the property at that location [42].

The geo-atoms can form geo-objects. The geo-objects are an aggregation of the locations whose geo-atoms meet certain properties [42]. The dimensionality of the geo-objects depends on the space in which these objects are embedded. To represent the interactions between the locations of geo-atoms, Goodchild et al. [42] proposed the concept of geo-dipole represented by the tuple, as follows:

$$
<x_{1}, x_{2}, Z, z\left(x_{1}, x_{2}\right)>
$$

where $z\left(x_{1}, x_{2}\right)$ represents the property $Z$ values for a pair of locations $x_{1}$ and $x_{2}$. The geo-dipole considers a pairwise interaction [43] and is the basic representation of spatial interaction.

We propose that the concepts of geo-atoms, geo-objects, and geo-dipoles can be translated to a pro-social perspective. A geo-atom may be an individual, a person with a specific feature, located 
in a specific space and time. Following a similar notation as the geo-atom, a 'geo-individual' can be described as follows:

$$
<v, A, a(v)>
$$

where $v$ is a vector that describes the position of the individual in the space-time dimension, $A$ represents the life-ability of the individual, and $a(v)$ represents her/his life-ability at a specific location in the space-time dimension.

At the social level, the concept of the geo-dipole is restricted. A social interrelation can be described by two or more people. The concept of geo-multipole, introduced by Zhu et al. [43], incorporates $N$ neighbors for a location $x$, as follows:

$$
<x_{1}, t_{N}, Z, z\left(x_{1}, t_{N}\right)>
$$

where $t_{N}$ is $x_{2}, x_{3}, \ldots, x_{N}$ are neighbors of $x_{1}$.

We propose the concept of 'geo-social' as the interactions of one geo-individual to her/his geo-individuals neighbors. A geo-social can be represented as follows:

$$
<v, t_{N}, A_{N}, a\left(v, t_{N}\right)>
$$

where $A_{N}$ is the life-abilities of the geo-individual and her/his geo-individual neighbors.

Cova and Goodchild [44] described that object fields could be seen as the relationship between one field-based space and an object-based space. A field-based space is a plane where every location is assigned a value from an attribute domain, while an object-based space is an object with specific identity, spatial embedding, and attributes [44]. We argue that geo-socials act as objects that represent the life-abilities of social networks in the space-time dimension, and that the field where each geo-social can be mapped can be called the 'livability-field'. Thus, the quality of life in a city can be represented by geo-socials embedded in a livability-field, where each of the geo-socials share common contextual features of the livability-field. For instance, geo-socials with similar levels of education and health could be related to context-based dimensions of the livability-field, such as green areas or clean air.

To achieve quality of life, the geo-social needs to act as barrier to social isolation or fragmentation. Thus, the interactions of two or more geo-individuals need to construct trust and cooperation.

Bona fide objects are constructed with the aim of reflecting internal homogeneity [42], while fiat objects depend on human demarcation decisions [45,46]. The geo-social can be a bona fide object and a fiat object. The parameter $v$ of the geo-social is defined by a fiat definition. However, we propose that the sense of place of the geo-social can be expressed by applying the uncertain conceptual spaces approach $[47,48]$. This approach aims that the geo-atom location parameter $x$ can be changed to a parameter that represents an infinite collection of conceptual spaces. The potentiality of this approach is to create a link between the locations in physical and conceptual space, such as a sense of place. For the geo-social, the parameter, $v$, that defines a location in space-time can be enriched by a place-based perspective, as follows:

$$
<f(v, p), t_{N}, A_{N}, a\left(f(v, p) t_{N}\right)>
$$

where $p$ represents the senses of places that a geo-individual and her/his neighbors may experience at location $v$. Thus, the geo-social can also be interpreted as a bona fide object, where it is assumed that the sense of place of cooperative geo-individuals defines a spatial homogeneity that could be expressed in the livability-field.

Figure 3 shows the fiat and bona fide natures of geo-socials. The geo-socials (grey shapes on the object space) in a specific space-time vary in terms of the life-abilities of the geo-individuals and their senses of place (bona fide). A single location (fiat) is not necessarily a point. The scale of analyses influences the definition of the geo-social. The geo-social may be represented at a household level (e.g., social interactions between the family members) or at a neighborhood level (e.g., social interactions between neighbors). In this case, the livability-field is scale-dynamic and 
context-dependent. Wu and $\mathrm{Li}$ [49] proposed that the dimensions of the scale are time, space, and the organizational level. These three dimensions form a cube where a specific phenomenon or process is embedded. The time reveals when the phenomenon is occurring, the space is the scale of the phenomenon (e.g., local, regional, global), and the organizational level denotes the components of the phenomenon. For instance, Kienberger et al. [50] proposed that the scale dimension of the organizational level for the 'phenomenon of vulnerability' is composed of diverse factors, such as institutional, socio-economic, and environmental factors. Regarding the dimensions of scale for our conceptual background, we propose that the livability-field can be adapted as the space dimension, a homogeneous area where geo-socials interact at a specific scale (household, neighborhood/community, and city). In this case, the livability-field is particularly different to the traditional fields in geo-information theories, because it is considered as the space of people's interactions and connections through the geo-socials. The dimension of time can be expressed in hours, days, weeks, and so on. The organizational level dimension is based on the place-based perspective of the geo-social (their senses of places $p$ ) and the life-abilities, $A_{N}$, of the geo-individuals (Figure 4).

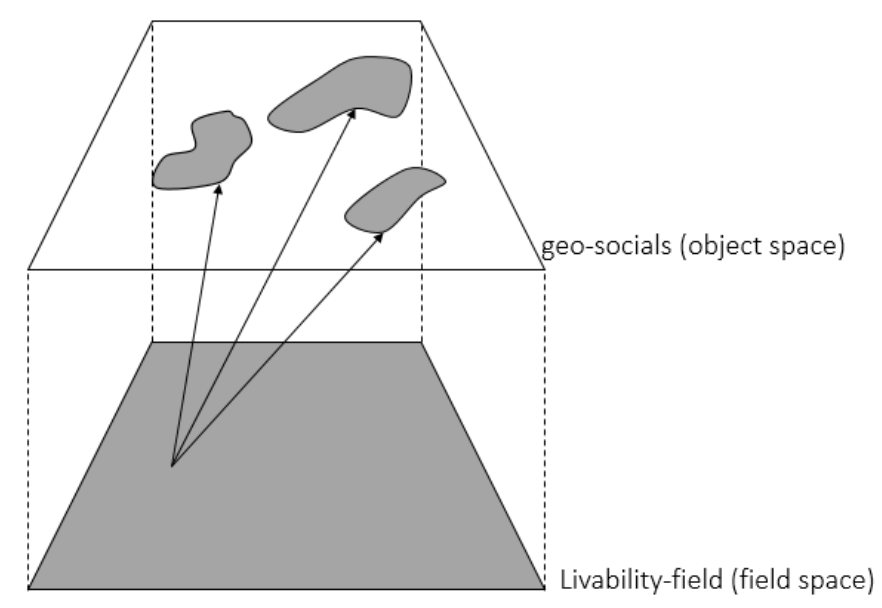

Figure 3. Relationship between the livability-field and the geo-social. The figure is inspired by the 'one location to many objects' relationship proposed by Cova and Goodchild [44].

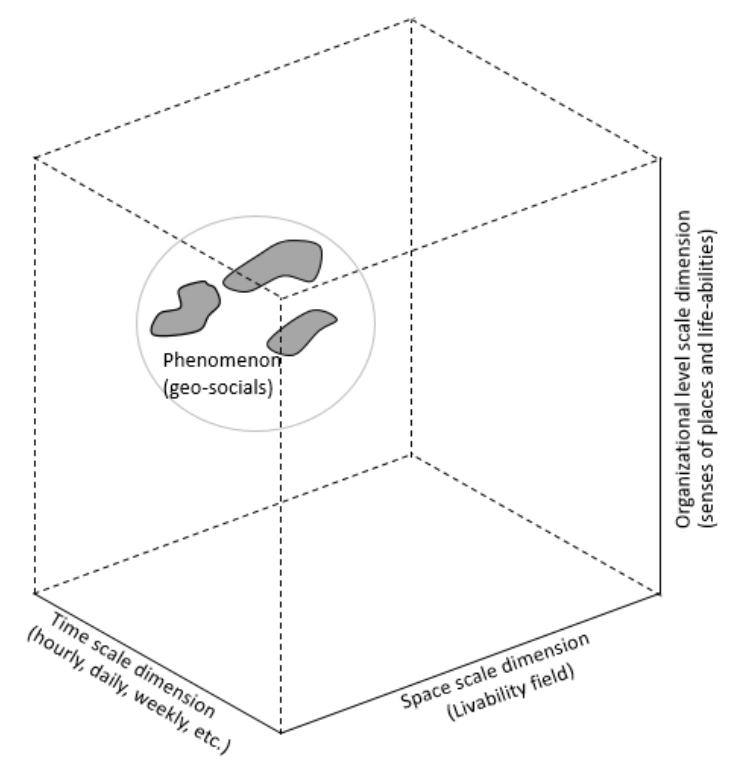

Figure 4. The scale dimensions cube for the conceptual urban quality space-place framework. 


\section{The Meaning of Smart City in the Conceptual Urban Quality Space-Place Framework}

Smart cities have been traditionally interpreted as cities that use smart computing technologies (e.g., software systems, and server and network infrastructures) to make urban services and infrastructures more intelligent and efficient [51]. However, technology is only one of the dimensions of smart cities, and the human dimension is considered a key driver of the smart city [52]. Smarter human communities are equivalent to smarter cities, and are communities that strengthen human bonds and services [53]. Socially segregated cities show symptoms of social disorder, which causes diverse problematics, such as crime or illness $[33,53]$ Thus, the idea of smart cities can be associated with citizens that are active and aware of the need of integration and cooperation. The governance dimension and the live-city dimension are citizen-centric dimensions related to cooperation, participation, and a capacity for adaptation [54]. In this sense, one of the challenges of a smart city is to have creative and educated citizens; citizens that are engaged enough and have the proper knowledge to construct the human dimensions of smart cities [55]. Furthermore, smart cities' technologies could act as links between 'atomic' individuals to create potentially happier communities connected in new ways [56]. The previous approaches to smart cities clearly express that the 'smart' aspect of a city is about the people. The urban quality space-place conceptual framework proposed in this article can be considered as a human-and-citizen-centric approach to smart cities. This approach has a connection to geo-information. Geo-information facilities, such as location-based services, platforms of maps, or Open GIS, facilitate citizen participation and support citizens with the knowledge of useful information in order to improve their communities. Therefore, the geo-individuals are individuals that are spatially enabled and have the capacity to build informed communities with implications for the functionality and governance of a city. In this sense, our conceptual framework may support a community-based view of city policies and spatial planning; the geo-socials are constructed by active and empowered geo-individuals to propose bottom-up solutions for the city. In the context of geo-information, Goodchild [57] argued that individual-level volunteered geographic information (VGI) may not be accurate, but collectively can have an important impact on the geo-information applied to public interests. We argue that the geo-socials can be used as the conceptual representation of citizen science. Citizen science would be inefficient with isolated geo-individuals, because interaction is one of the basic requirements to apply VGI for a specified purpose [58]. Citizen science describes communities of citizens who report and monitor the phenomena of different domains of knowledge [57].

The communities of citizens represented by the geo-socials allow for the spatial enablement of the livability-field, where the dynamics of the sense of place and the construction of the space use geo-information as a common good. Here, geo-information is not seen as the origin of plain data-driven geographies, but as an opportunity to conceive citizen-driven spatialities that look for the development of a pluralistic livability-field through the creation of public spaces of quality, where the citizens experience happiness and ownership of the space. The notions of geo-socials and the livability-field overcome atomistic views of human behavior. In the context of VGI and citizen science, we consider it important to apply our concept of geo-socials to the social media-based information, to obtain insights for community-based solutions and urban planning. For instance, the GeoCitizen platform is a type of social network where citizens are able to geo-reference problematics affecting their neighborhoods and also propose initiatives to improve their quality of life [59]. Other popular social networks, such as Twitter, offer useful geo-referenced information to work with locational 'senses of place' in the urban context. For instance, an analysis using Twitter data has been applied to identify urban planning-related spatial patterns of positive and negative sentiments of London's residents and visitors regarding the organization of the Olympic Games [60]. The uncertain conceptual spaces approach integrated in our geo-social definition may be useful to visualize the connections of the properties in the physical space (locations) to properties in conceptual space (sense of place) as a means to studying the smartness of the city. The geo-socials and the livability-field are also an opportunity to re-think the representation of place values in the space. The different senses of places incorporated in 
the geo-socials recognize the diverse individual and collective place attachments that people have in a city.

All in all, for the conceptual framework presented in this paper, a smart city means a human-centered, livable city in constant transformation; a city with strong social and community bonds, bonds that are facilitated with the support of geo-information and technology. In this sense, the notion of the smart city relies not only on technology, but on empowered citizens that trust each other and can cooperate.

\section{Future Directions}

The conceptual urban quality space-place framework paves the road for many research avenues. One open question is the representation of the space-place enriched geo-social in a geographic information system. Representing the geo-social in explicit spatial terms may be feasible. However, representing a collection of conceptual spaces (senses of places) is a challenge for future research. We consider that future research could translate the senses of places of the geo-socials into conceptual spaces with geometrical structure. A possible solution for this translation could be the application of Gärdenfors's domains of conceptual spaces [61]. He defines a conceptual space as a collection of domains, and a domain as a set of quality dimensions with properties that can be represented as a convex region. We envision the feasibility of representing geo-socials in livability-fields through a prototype-threshold approach, where spatial locations correspond to more than one concept and hierarchical relations between concepts can be represented [62]. Our conceptual framework is also flexible in terms of the time scale. An interesting topic for future work is to analyze different life-abilities and the senses of places of geo-socials through time units-hourly, daily, weekly, or monthly. We believe that social media data could be a useful source of information for developing time-series methodologies for the geo-socials.

Further research will investigate the construction of new ontologies to define the geo-social as a feature to be represented in the virtual world of geo-informatics. The construction of ontologies from perceived space can facilitate the structuring of information in spatial databases for urban planning [63]. Here, the challenge is to incorporate in the spatial representation of the geo-social the varied cultural backgrounds that the geo-individuals may have. Additionally, the definition of spatial topologies for our conceptual framework is a promising field of study for the future. Previous work has adapted topological spatial relationships between the sense of place and social capital in an urban context [25]. We consider that these topological relationships could be a reference to develop more complex topological relationships for our conceptual framework, because of the multilevel and multidimensional nature of the geo-individuals, geo-socials, and the livability-field. In the context of our conceptual framework, the exploration of non-Euclidean spatial ontologies and topologies (e.g., fractal spaces) may be an opportunity to open a new road of research in quality-of-life studies in the city.

We also consider it important to analyze how the life-abilities of the geo-individual may influence one another. For this, we argue that future studies related to this paper need to focus on multi-scale analyses defining individual level and community level variables for the life-ability and the livability dimensions. Real-world gathered citizen's data can be employed for this purpose. Further research may also explore the level of membership of the senses of places of the geo-social in relation to a location. This work would need the application of fuzzy and multi-criteria analyses. We also envision that the proposed framework could serve as a design principle for modeling the complexity of the city. The low-entropy city needs to be based on a flexible interactive network of agents [38]. Thus, future investigations could model sets of agents (individuals) with high levels of autonomy, adaptivity, and (place) sense-making. These models could even have important implications for the development of artificial intelligence.

Future works related to this paper also need to explore geo-information capabilities to understand the importance of public spaces as opportunities to construct cohesive cities. In this sense, 
the objectivity of geo-information needs to be expanded to the subjectivity of the social construction of the space. Finally, we hope the conceptual urban quality space-place framework will act as a base to develop the participatory public geographic information systems to support citizen participation and engagement, as well as to support urban planning based on the citizens' senses of place.

\section{Conclusions}

We consider that the conceptual framework presented in this paper provides a valuable foundation for coupling applied geo-information with a humanistic perspective to support urban planning. Moreover, we argue that improving quality of life could be considered as the ultimate goal of urban policy and planning. Spatial analyses could consider the presented urban quality space-place conceptual framework, because it is able to account for more key aspects of human conceptions of space than traditional geographic information systems approaches. This paper is also a contribution to urban and geographic information science epistemologies by linking the widely discussed concepts of geo-information and quality of life. Thinking and developing integrated, pluralistic, and holistic conceptual frameworks can facilitate the development of tools, algorithms, and, perhaps, technologies, inspired by the dimensions of livability and life-ability, as well as being inspired by the importance of the value of the symbolic and subjective meanings of space-the concept of place. We believe that the concepts of the geo-socials and geo-individuals encompass principles for inclusive urban societies, considering contextual and individuals' characteristics, such as quality of public space, social capital, and social cohesion.

This conceptual framework also emphasizes the importance of spatial thinking to better understand the complexity of human-environmental interactions in the city. The study of cities applying geo-information does not need to be entirely about bytes and pixels. We need to think and re-think our views and concepts of the world, of the city where we live, and of our neighborhood. We need to first develop and improve epistemologies in order to have robust conceptual frameworks as the base for developing models and algorithms. Otherwise, we could be creating models and algorithms that only see numbers, and not competent individuals with the potentiality of cooperating with one another and with the capacity of building livable urban communities.

Author Contributions: P.F.C.-B. conceived, designed, and wrote most of the paper. H.M. supported P.F.C.-B. with ideas to clarify the explanation of the conceptual framework, particularly contributing to the introduction section.

Funding: This research received no external funding.

Conflicts of Interest: The authors declare no conflict of interest.

\section{References}

1. Harrison, S.; Dourish, P. Re-place-ing Space: The roles of place and space in collaborative systems. In Proceedings of the 1996 ACM Conference on Computer Supported Cooperative Work, Boston, MA, USA, 16-20 November 1996; ACM: New York, NY, USA, 1996; pp. 67-76.

2. Alberti, M.; Marzluff, J.M.; Shulenberger, E.; Bradley, G.; Ryan, C.; Zumbrunnen, C. Integrating Humans into Ecology: Opportunities and Challenges for Studying Urban Ecosystems. In Urban Ecology: An International Perspective on the Interaction between Humans and Nature; Marzluff, J.M., Shulenberger, E., Endlicher, W., Alberti, M., Bradley, G., Ryan, C., Simon, U., ZumBrunnen, C., Eds.; Springer: Boston, MA, USA, 2008; pp. 143-158, ISBN 978-0-387-73412-5.

3. Wei, C.; Blaschke, T. Pixel-Wise vs. Object-Based Impervious Surface Analysis from Remote Sensing: Correlations with Land Surface Temperature and Population Density. Urban Sci. 2018, 2, 2. [CrossRef]

4. Brenner, N.; Schmid, C. Towards a new epistemology of the urban? City 2015, 19, 151-182. [CrossRef]

5. Graham, S. The end of geography or the explosion of place? Conceptualizing space, place and information technology. Prog. Hum. Geogr. 1998, 22, 165-185. [CrossRef]

6. Agnew, J. Space and Place. In Handbook of Geographical Knowledge; Agnew, J., Livingstone, D., Eds.; Sage: London, UK, 2011. 
7. Yamaguchi, A. Influences of Quality of Life on Health and Well-Being. Soc. Indic. Res. 2015, 123, 77-102. [CrossRef]

8. Marans, R.W.; Stimson, R. An overview of quality of urban life. In Investigating Quality of Urban Life: Theory, Methods, and Empirical Research; Marans, R.W., Stimson, R.J., Eds.; Springer: Dordrecht, The Netherlands, 2011; pp. 1-29.

9. Glatzer, W. Monitoring and Analyzing Quality of Life-An Introduction. In Global Handbook of Quality of Life: Exploration of Well-Being of Nations and Continents; Glatzer, W., Camfield, L., Møller, V., Rojas, M., Eds.; Springer: Dordrecht, The Netherlands, 2015; pp. 1-11.

10. Sen, A. Collective Choice and Social Welfare; Holden-Day: San Francisco, CA, USA, 1970.

11. McCrea, R.; Shyy, T.-K.; Stimson, R. What is the strength of the link between objective and subjective indicators of urban quality of life? Appl. Res. Qual. Life 2006, 1, 79-96. [CrossRef]

12. van Kamp, I.; Leidelmeijer, K.; Marsman, G.; de Hollander, A. Urban environmental quality and human well-being: Towards a conceptual framework and demarcation of concepts; a literature study. Landsc. Urban Plan. 2003, 65, 5-18. [CrossRef]

13. Brereton, F.; Clinch, J.P.; Ferreira, S. Happiness, geography and the environment. Ecol. Econ. 2008, 65, 386-396. [CrossRef]

14. Veenhoven, R. Happiness: Also Known as "Life Satisfaction" and "Subjective Well-Being". In Handbook of Social Indicators and Quality of Life Research; Land, K.C., Michalos, A.C., Sirgy, M.J., Eds.; Springer: Dordrecht, The Netherlands, 2012; pp. 63-77, ISBN 978-94-007-2421-1.

15. Mulligan, G.; Carruthers, J.; Cahill, M. Urban quality of life and public policy: A survey. Contrib. Econ. Anal. 2004, 266, 729-802. [CrossRef]

16. Shafer, C.S.; Lee, B.K.; Turner, S. A tale of three greenway trails: User perceptions related to quality of life. Landsc. Urban Plan. 2000, 49, 163-178. [CrossRef]

17. Veenhoven, R. The Four Qualities of Life. J. Happiness Stud. 2000, 1, 1-39. [CrossRef]

18. Harvey, D. Social Justice and the City; Johns Hopkins University Press: Baltimore, MD, USA, 1973.

19. Isard, W. Location and Space-Economy; MIT Press: Cambridge, MA, USA, 1956.

20. Lefebvre, H. The Production of Space; Anthopos: Paris, France, 1991.

21. Massey, D. Power-Geometries and the Politics of Space-Time (Hettner Lecture 1998); University of Heidelberg, Institute of Geography: Heidelberg, Germany, 1999.

22. Entrikin, J.N. The Betweenness of Place: Towards a Geography of Modernity; Johns Hopkins University Press: Baltimore, MD, USA, 1991.

23. Jorgensen, B.; Stedman, R. Sense of Place as an Attitude: Lakeshore Owners Attitudes toward their Properties. J. Environ. Psychol. 2001, 21, 233-248. [CrossRef]

24. William, W. City: Rediscovering the Center; Doubleday: New York, NY, USA, 1988.

25. Acedo, A.; Painho, M.; Casteleyn, S. Place and city: Operationalizing sense of place and social capital in the urban context. Trans. GIS 2017, 21, 503-520. [CrossRef]

26. Dourish, P. Re-space-ing Place: "Place" and "Space" Ten Years on. In Proceedings of the 2006 20th Anniversary Conference on Computer Supported Cooperative Work (CSCW '06), Banff, AB, Canada, 4-8 November 2006; ACM: New York, NY, USA, 2006; pp. 299-308.

27. Crang, M.; Travlou, P.S. The City and Topologies of Memory. Environ. Plan. D Soc. Space 2001, 19, 161-177. [CrossRef]

28. Williams, A.; Dourish, P. Imagining the City: The Cultural Dimensions of Urban Computing. Computer 2006, 39, 38-43. [CrossRef]

29. Alberti, M. The Effects of Urban Patterns on Ecosystem Function. Int. Reg. Sci. Rev. 2005, 28, $168-192$. [CrossRef]

30. Lefebvre, H. Le Droit à la Ville; Anthopos: Paris, France, 1968.

31. Augé, M. Non-Places: Introduction to the Anthropology of Supermoderntiy; Verso: London, UK, 1995.

32. Soja, E.W. The City and Spatial Justice; Justice Spatial/Spatial Justice: Paris, France, 2009; pp. 1-5.

33. Allardyce, J.; Gilmour, H.; Atkinson, J.; Rapson, T.; Bishop, J.; McCreadie, R.G. Social fragmentation, deprivation and urbanicity: Relation to first-admission rates for psychoses. Br. J. Psychiatry 2005, 187, 401-406. [CrossRef] [PubMed]

34. Harpham, T.; Grant, E.; Thomas, E. Measuring social capital within health surveys: Key issues. Health Policy Plan. 2002, 17, 106-111. [CrossRef] [PubMed] 
35. Lebel, A.; Pampalon, R.; Villeneuve, P.Y. A multi-perspective approach for defining neighbourhood units in the context of a study on health inequalities in the Quebec City region. Int. J. Health Geogr. 2007, 6, 27. [CrossRef] [PubMed]

36. Bailey, K.D. Social Entropy Theory: An overview. Syst. Pract. 1990, 3, 365-382. [CrossRef]

37. Cabral, P.; Augusto, G.; Tewolde, M.; Araya, Y. Entropy in Urban Systems. Entropy 2013, 15, 5223-5236. [CrossRef]

38. Pelorosso, R.; Gobattoni, F.; Leone, A. The low-entropy city: A thermodynamic approach to reconnect urban systems with nature. Landsc. Urban Plan. 2017, 168, 22-30. [CrossRef]

39. Wilson, S.; Hutson, M.; Mujahid, M. How Planning and Zoning Contribute to Inequitable Development, Neighborhood Health, and Environmental Injustice. Environ. Justice 2008, 1, 211-216. [CrossRef]

40. Goodchild, M.F. Twenty years of progress: GIScience in 2010. J. Spat. Inf. Sci. 2010, 3-20. [CrossRef]

41. Hägerstrand, T. What about people in regional science? Pap. Reg. Sci. 1970, 24, 7-24. [CrossRef]

42. Goodchild, M.F.; Yuan, M.; Cova, T.J. Towards a general theory of geographic representation in GIS. Int. J. Geogr. Inf. Sci. 2007, 21, 239-260. [CrossRef]

43. Zhu, R.; Kyriakidis, P.C.; Janowicz, K. Beyond Pairs: Generalizing the Geo-dipole for Quantifying Spatial Patterns in Geographic Fields. In Societal Geo-Innovation, Proceedings of the AGILE 2017, Orlando, FL, USA, 7-11 August 2017; Bregt, A., Sarjakoski, T., van Lammeren, R., Rip, F., Eds.; Springer: Cham, Switzerland, 2017; pp. 331-348.

44. Cova, T.J.; Goodchild, M.F. Extending geographical representation to include fields of spatial objects. Int. J. Geogr. Inf. Sci. 2002, 16, 509-532. [CrossRef]

45. Smith, B.; Varzi, A.C. Fiat and Bona Fide Boundaries. Philos. Phenomenol. Res. 2000, 60, 401-420. [CrossRef]

46. Vogt, L.; Grobe, P.; Quast, B.; Bartolomaeus, T. Fiat or Bona Fide Boundary-A Matter of Granular Perspective. PLoS ONE 2012, 7, e48603. [CrossRef] [PubMed]

47. Ahlqvist, O. A Parameterized Representation of Uncertain Conceptual Spaces. Trans. GIS 2004, 8, 493-514. [CrossRef]

48. Ahlqvist, $\mathrm{O}$. The geo-attribute space: A general space-time-property representation. In Proceedings of the 9th International Conference on GeoComputation, Maynooth, Ireland, 3-5 September 2007; National University of Ireland: Maynooth, Ireland, 2007.

49. Wu, J.; Li, H. Concepts of scale and scaling. In Scaling and Uncertainty Analysis in Ecology; Wu, J., Jones, K.B., Li, H., Loucks, O., Eds.; Springer: Dordrecht, The Netherlands, 2006; pp. 1-13.

50. Kienberger, S.; Blaschke, T.; Zaidi, R.Z. A framework for spatio-temporal scales and concepts from different disciplines: The "vulnerability cube". Nat. Hazards 2013, 68, 1343-1369. [CrossRef]

51. Washburn, D.; Sindhu For Cios, U. Helping CIOs Understand "Smart City" Initiatives: Defining the Smart City, Its Drivers, and the Role of the CIO; Forrester Research: Cambridge, MA, USA, 2010.

52. Nam, T.; Pardo, T.A. Conceptualizing smart city with dimensions of technology, people, and institutions. In Proceedings of the 12th Annual International Conference on Digital Government Research, College Park, MD, USA, 12-15 June 2011; pp. 282-291.

53. Kanter, R.M.; Litow, S.S. Informed and Interconnected: A Manifesto for Smarter Cities; Harvard Business School: Boston, MA, USA, 2009.

54. Roche, S. Geographic Information Science I: Why does a smart city need to be spatially enabled? Prog. Hum. Geogr. 2014, 38, 703-711. [CrossRef]

55. Degbelo, A.; Granell, C.; Trilles, S.; Bhattacharya, D.; Casteleyn, S.; Kray, C. Opening up Smart Cities: Citizen-Centric Challenges and Opportunities from GIScience. ISPRS Int. J. Geo-Inf. 2016, 5, 16. [CrossRef]

56. Kamel Boulos, M.N.; Tsouros, A.D.; Holopainen, A. 'Social, innovative and smart cities are happy and resilient': Insights from the WHO EURO 2014 International Healthy Cities Conference. Int. J. Health Geogr. 2015, 14, 3. [CrossRef] [PubMed]

57. Goodchild, M.F. Citizens as sensors: The world of volunteered geography. GeoJournal 2007, 69, $211-221$. [CrossRef]

58. Connors, J.P.; Lei, S.; Kelly, M. Citizen Science in the Age of Neogeography: Utilizing Volunteered Geographic Information for Environmental Monitoring. Ann. Assoc. Am. Geogr. 2012, 102, 1267-1289. [CrossRef]

59. Atzmanstorfer, K.; Resl, R.; Eitzinger, A.; Izurieta, X. The GeoCitizen-approach: Community-based spatial planning-An Ecuadorian case study. Cartogr. Geogr. Inf. Sci. 2014, 41, 248-259. [CrossRef] [PubMed] 
60. Kovács-Győri, A.; Ristea, A.; Havas, C.; Resch, B.; Cabrera-Barona, P. \#London2012: Towards citizen-contributed urban planning through sentiment analysis of twitter data. Urban Plan. 2018, 3. [CrossRef]

61. Gärdenfors, P. Conceptual Spaces: The Geometry of Thought; The MIT Press: Cambridge, MA, USA, 2004.

62. Lewis, M.; Lawry, J. Hierarchical conceptual spaces for concept combination. Artif. Intell. 2016, 237, $204-227$. [CrossRef]

63. Wang, J.; Worboys, M. Ontologies and representation spaces for sketch map interpretation. Int. J. Geogr. Inf. Sci. 2017, 31, 1697-1721. [CrossRef]

(C) 2018 by the authors. Licensee MDPI, Basel, Switzerland. This article is an open access article distributed under the terms and conditions of the Creative Commons Attribution (CC BY) license (http:/ / creativecommons.org/licenses/by/4.0/). 